\title{
Application of Financial Cloud in the Sustainable Development of Smart Cities
}

\author{
Yangchun Cao, Guangyu Zhang $\mathbb{D}^{\mathrm{D}}$, and Chunyao Ou \\ School of Management, Guangdong University of Technology, Guangzhou 510520, China \\ Correspondence should be addressed to Guangyu Zhang; 1111908005@mail2.gdut.edu.cn
}

Received 4 September 2020; Revised 27 September 2020; Accepted 30 September 2020; Published 13 October 2020

Academic Editor: Wei Wang

Copyright ( $) 2020$ Yangchun Cao et al. This is an open access article distributed under the Creative Commons Attribution License, which permits unrestricted use, distribution, and reproduction in any medium, provided the original work is properly cited.

\begin{abstract}
This article first investigates the status of financial cloud development in smart cities and studies the sustainable development of smart cities. Secondly, it investigates the construction of the evaluation model, using the power of the financial cloud, through exploratory factor analysis, selecting the principal component analysis method to extract the factors, for screening and dimensionality reduction of the indicators, and making hypotheses. We used confirmatory factor analysis to establish the structural equation. The measurement model analyzes and validates the assumptions of the previous stage and finally determines the sustainable development evaluation index system. Then, starting from the scoring coefficient matrix of the exploratory factor analysis of the final model, the variance contribution rate of each common factor is weighted to construct a comprehensive evaluation model to calculate the comprehensive evaluation score. For the comprehensive evaluation score of the sustainable development level of the smart city, SPSS software performs cluster analysis, performs regional clustering, and determines the level of urban development. Finally, by comparing the sustainable development levels of smart cities, the related causes of the gaps are analyzed. Key factors affecting the sustainable development of smart cities are identified, and corresponding countermeasures are proposed.
\end{abstract}

\section{Introduction}

In recent years, the concept of smart city has been vigorously promoted in the direction and concept of urban construction in various countries in the world, and it has set off a wave [1-3]. Many places in life have applications of smart technologies, and they are becoming more and more intelligent in medicine, transportation, electricity, food, currency, retail, infrastructure, and cities, which also makes the earth continue to move toward the field of intelligence [4]. "Smart Earth" has driven the enthusiasm of countries to create intelligent cities. Carrying out smart city construction has become a consensus on the development of advanced cities and economic society with informatization levels and has become an important method and approach for many cities to achieve urban cross-domain development, improve urban public service levels and urban operating efficiency, and develop strategic emerging industries [5]. Many managers and city decision-makers in various countries around the world regard the construction of smart cities as the key to sustainable development of resources and the environment and scientific urban management. Various banks have tried to build smart outlets [6]. Although the official names or specific forms of smart bank outlets are slightly different, the development direction of "brain outlet smart transformation" has become the consensus of the banking channel transformation. It plays a huge role in urban construction [7].

The emerging thing of financial technology is especially important to the financial industry, so researchers from all sides pay high attention to it. International organizations, sovereign countries, and research scholars have conducted in-depth research on the meaning of financial technology, but they have not yet formed a unified opinion on the definition of financial technology [8]. Among them, International Financial Stability Council defines fintech as the use of technological means to promote financial business innovation, forming business models, technology applications, 
processes and products that have a significant impact on financial markets, institutions and financial services [9]. The definition of financial technology is not limited to the perspective of science and technology, but also pays more attention to the innovation of financial enterprises brought about by the application of technology [10]. Masera et al. pointed out that global fintech research can help promote the efficiency of financial banking business services, reduce transaction costs, and form economies of scale [11]. Panori et al. pointed out that, in data-driven credit, borrowing is gradually no longer a unique field of banks [12]. Xie et al. have a significant impact on the development of the banking industry and financial supervision models and have a significant effect in the construction planning of ecological smart cities [13].

Since the development of the smart city, it has entered a new normal state: from concept to implementation, application close to people's livelihood, open urban public resource data, and government-enterprise cooperation to activate urban energy [14]. The soft power of environmental improvement has been enhanced. Kong et al. pointed out that a networked city is equivalent to a smart city, so the most obvious sign of this smart city is the Internet of Things [15]. Eckhoff and Wagner pointed out that, to build a smart city, it is necessary to increase the utilization rate of informatization-related technologies, coordinate various functional departments, improve and arrange existing resources, optimize services, strengthen greening, build a harmonious society, and promote sustainable urban development [16]. Enterprises and the masses create an excellent working, living, and entertainment atmosphere. The establishment of this environment is reflected in aspects of urban transportation system, command center, resource management system, safety in public places, and environmental protection [17]. Professor Xu and Geng vividly pointed out that smart cities are the sum of digital cities and the Internet of Things [18]. It is emphasized that the construction of smart cities is based on modern information and communication technology [19]. Human wisdom and attitude will make intelligent objects better understand people and complement each other's wisdom, thus building this service relationship in economic and social activities [20].

To sum up, the evaluation system for sustainable development of smart cities can allow researchers to understand the degree of smartness and sustainable development of the city horizontally and vertically. Different countries or cities have different evaluation index systems. With the rapid development of Internet finance, emerging online personal finance products have grown rapidly, which has a strong impact on the entire traditional financial industry. Internet finance has changed the living environment of commercial banks and changed people's payment and financial management habits. With the increasing popularity of Internet finance, concepts such as big data and precision marketing are well known and valued. Based on the financial cloud, this article conducts research on the sustainable development of smart cities, and fintech and banking channel management innovation are gradually integrated and developed.

\section{Smart City Construction under the Financial Cloud}

2.1. Smart Finance Cloud. Financial cloud is an industry cloud application scenario. It uses cloud computing technology to deploy financial products, information, and services to the cloud network to improve the overall efficiency of financial institutions, improve processes, reduce operating costs, and provide customers with more convenience. Financial business services and financial information service [21]. The goal of smart city construction is to optimize existing resources through analysis, monitoring, integration, and intelligent response through the use of next-generation information technology to make city operations more efficient, safer, and greener. From the perspective of the overall technical framework of a smart city, it can be divided into four layers from the bottom up: the perception base layer, the network middle layer, the platform layer, and the smart application layer [22]. The basic layer of perception, that is, the smart city, needs to obtain information by sensing the city, compare it to the human sensory organ, and place various sensing devices (mobile phones, sensor nodes, personal computers, PDA, radio frequency tags, and monitoring probes) in the city. Among them, the chemical or physical changes of the monitored objects are converted into information and passed to the next layer. These sensing devices can not only monitor the city in real time, but also provide information feedback to them, which has the performance of two-way conduction. To enable the perception layer to perceive the city, the perception equipment needs to be constantly updated and technically improved more accurately and comprehensively. The smart financial cloud panorama is shown in Figure 1.

The middle layer of the network is the "meridian" of the smart city. Through the wireless sensor network, cloud computing network, wireless LAN, telecommunications network, P2P network, Internet, Internet of Things, 3G, 4G, and other networks, the information obtained from the perception layer will be carried out. Process and pass to the next layer; the network layer has extensive connectivity, realize the interconnection of information resources between cities or countries, and form a channel for information transmission between cities. The platform layer uses cloud computing and other technologies to process the collected information, then reflects the changes of the various elements of the city in time, and feeds back the analysis results to the city decision-makers. The smart application layer is a smart city that provides services for citizens through the analysis and processing of information such as audio, video, cluster scheduling, and data collection, such as mobile wallet (scanning type), smart home, smart transportation, street light control (control type), logistics information, and environmental pollution (monitoring type). Connect massive data on city management and make smart city management automated, humanized, and intelligent. The application layer can be divided into a terminal device layer and an application program layer. The terminal device layer, that is, the human-machine interface, mainly implements human-computer interaction. Application program layer mainly performs data processing on all aspects of society and economy, including agriculture, banking, medicine, logistics, industry, electricity, home life, and others. 


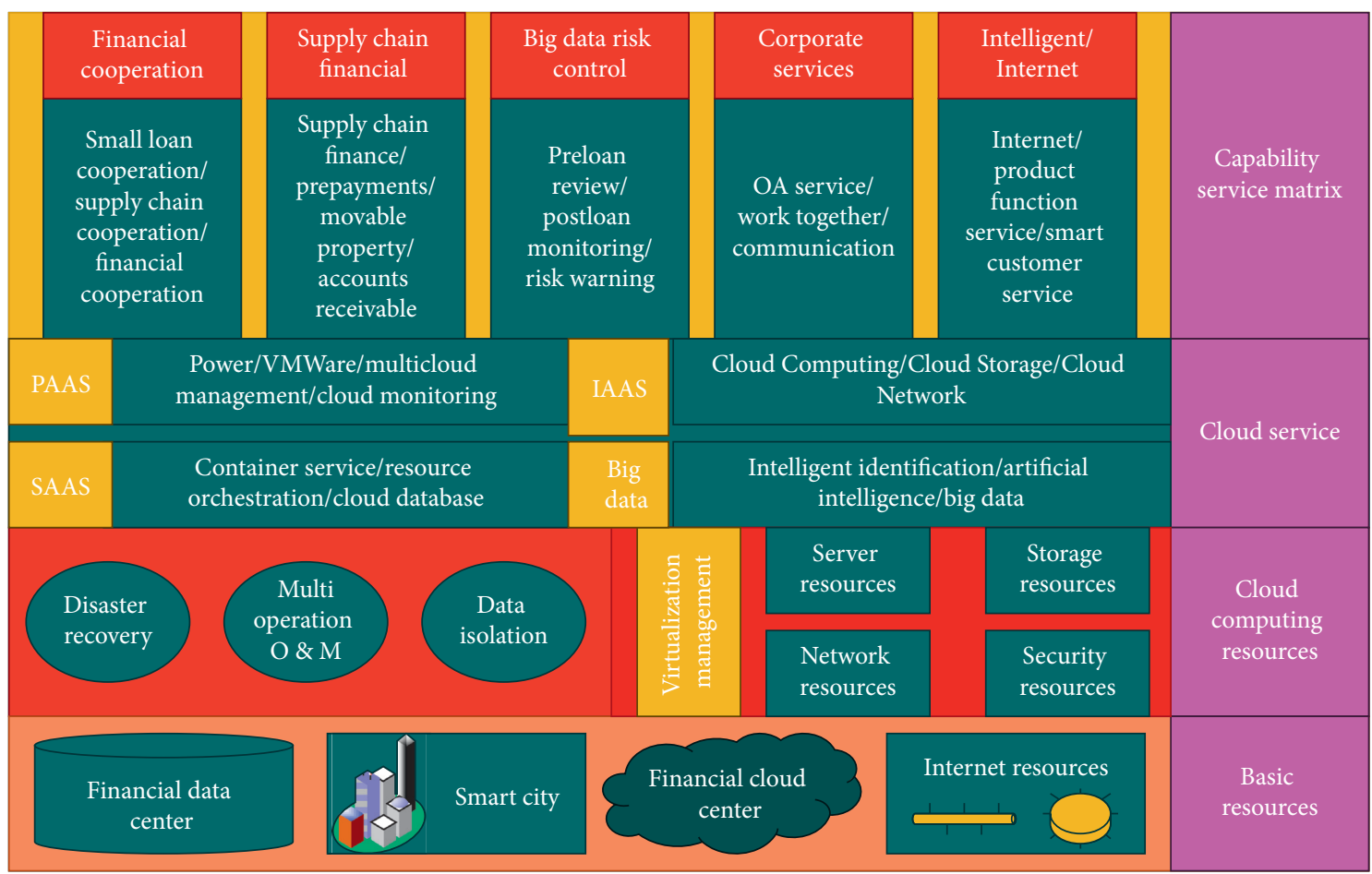

Figure 1: Smart financial cloud.

2.2. Smart City Financial Cloud Model. The construction of a smart city requires the interaction and interaction of the industrial ecological chain, information chain, innovation chain, financial chain, cultural chain, and service chain to form a complete smart city operation system that integrates human capital, infrastructure construction, and capital [23]. Resource elements are put into this system, and smart government, smart economy, and smart life have become the products of this system. The specific logical relationship is shown in Figure 2.

Enterprises and governments differ in the wisdom of city management. In the course of time, the government no longer values the advantages of intelligent construction of public services, but pays more attention to the potential and development of ICT, in addition to the effectiveness of city management after the use of its products.

In smart city operation and management, DMU is the decision-making unit, and there are $n$ number of participants that need to participate in the evaluation. The inputs and outputs of these DMUs are $m$ and $s$, respectively. The input vector of the $\mathrm{jth}$ DMU is $x_{j}=\left(x_{1 j}, \ldots, x_{m j}\right) T>$ $0(j=1, \ldots, n)$, and the output vector is $y_{j}=\left(y_{1 j}, \ldots\right.$, $\left.y_{s j}\right) T>0(j=1, \ldots, n)$. The weight coefficients of the output and input indicators of these decision-making units are $u=\left(u_{1}, \ldots, u_{s}\right) T, v=\left(v_{1}, \ldots, v_{m}\right) T$. The efficient evaluation index corresponding to each DMU is

$$
K_{j}=\frac{\sum_{r=1}^{s} u_{r} y_{r j}}{\sum_{i=1}^{n} v_{i} x_{i j}} .
$$

In the evaluation process, it is necessary to select appropriate index values. When the input values of some indicators are increased, all output values will be increased; when the values of other indicators are increased, some output values will be reduced. The output index project of the smart city is mainly divided into four parts: smart government, smart life, smart humanities, and smart economic development. The required input indicators are mainly divided into three parts: capital and human capital investment and infrastructure construction. Input indicators are divided into positive and negative. We define input indicators that have a positive impact on citizens' lives as positive input indicators, while indicators that have a negative impact on citizens' lives are defined as passive input indicators.

The construction of the Malmquist productivity index with reference to $t$ and $t+1$ period has made the Malmquist index widely used. The specific formula is as follows:

$$
\begin{aligned}
W\left(x^{t}, y^{t}, x^{t+1}, y^{t+1}\right)= & {\left[\frac{D c^{t}\left(x^{t+1}, y^{t+1}\right)}{D c^{t}\left(x^{t}, y^{t}\right)} \times \frac{D c^{t}\left(x^{t+1}, y^{t+1}\right)}{D c^{t+1}\left(x^{t}, y^{t}\right)}\right], } \\
W\left(x^{t}, y^{t}, x^{t+1}, y^{t+1}\right)= & \frac{D c^{t}\left(x^{t+1}, y^{t+1}\right)}{D c^{t}\left(x^{t}, y^{t}\right)} \times\left[\frac{D c^{t}\left(x^{t+1}, y^{t+1}\right)}{D c^{t}\left(x^{t}, y^{t}\right)}\right. \\
& \left.\times \frac{D c^{t}\left(x^{t+1}, y^{t+1}\right)}{D c^{t+1}\left(x^{t}, y^{t}\right)}\right]^{1 / 2} .
\end{aligned}
$$

This paper quantitatively analyzes the coupling and coordination relationship of the industrial-city integration of smart cities through the evaluation of the coupling coordination degree. After fully referring to the relevant research, a scientifically constructed coupling and coordinated evaluation model of smart city construction, industrial 


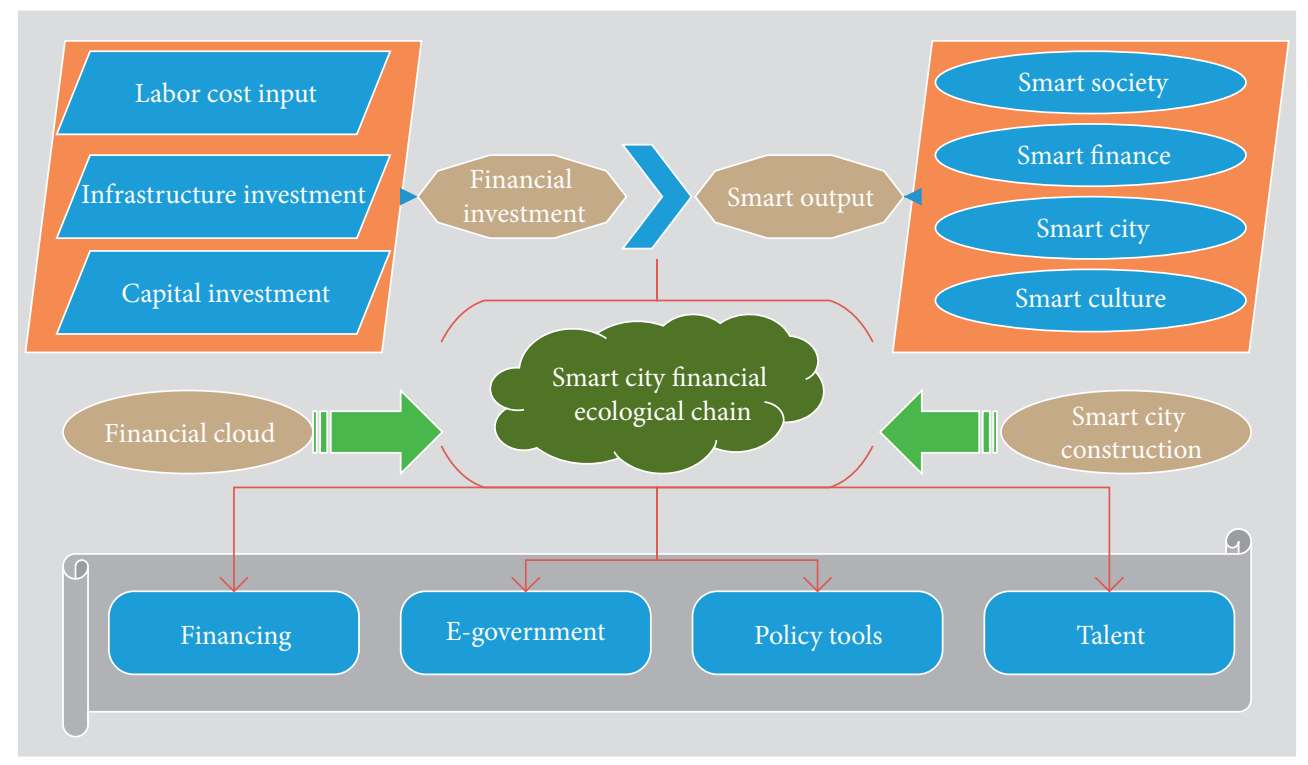

Figure 2: Schematic diagram of smart city financial investment.

development, and urban ecological protection are built. The specific formula is shown in

$$
T=\left\{\frac{\left(U_{1} \times U_{2} \times U_{3}\right)}{\left(U_{1}+U_{2}+U_{3}\right) \times\left(U_{1}+U_{2}+U_{3}\right)}\right\}^{1 / 3} .
$$

$C$ represents the degree of coupling between the smart city construction system, industrial development system, and ecological protection system. The level of development of a system is not proportional to the degree of coupling within the system, and there may be a low degree of coupling within the system of high-level development and vice versa. On this basis, we can revise the coupling model and measure the true coordination between the three systems to build a coordination model as follows:

$$
R=(C T)^{1 / 2}
$$

Indicators have a positive effect and a negative effect on the system. The unit of each indicator also has a certain difference. Each indicator needs to be processed before calculation. After determining the positive and negative directions of the index, use the following formula for data processing:

$$
\begin{aligned}
& v_{i j}=\frac{x_{i j}-\min \left(x_{i j}\right)}{\max \left(x_{i j}\right)-\min \left(x_{i j}\right)}, \\
& v_{i j}=\frac{\min \left(x_{i j}\right)-x_{i j}}{\max \left(x_{i j}\right)-\min \left(x_{i j}\right)} .
\end{aligned}
$$

Weight refers to the contribution rate of an indicator to the entire indicator system. Only after determining the weight can the system be reasonably measured. In this paper, the weight of the entropy method is used to determine the weight. The formula is as follows:

$$
H_{i=1,2,3}=\sum_{j=1}^{m} \lambda_{i j} u_{i j}
$$

All the subsystems of the smart city ecosystem need to build a comprehensive information platform to realize the interaction and link of information between the smart city and the industry. The industrial development goals of smart cities are different from other cities. The pillar industries of cities should focus on the cultivation of smart industries. Through resource integration and high-tech support for smart cities, as well as the creation of a market environment, the industry's supporting cooperation will be fully utilized for urban construction. The "Innovation + Entrepreneurship" dual-innovation platform relies on the joint action of smart city innovation elements, innovation awareness, and innovation capabilities. Innovation is the vitality of smart cities. Entrepreneurship injects fresh blood into smart cities, and cities create incisiveness for "double innovation" social environment. The informatization industry is the leader of cities towards wisdom, emphasizing that informatization technology, informatization industry, and informatization services not only promote the development of smart cities, but also promote the development of smart cities and coordinated development of industries and cities. The coordinated integration of ecological chain resources further builds a more complete "ecological circle" of smart city industry-city integration to achieve full utilization of city functions and industrial development and maximize sharing of information technology (Figure 3).

2.3. Sustainability Evaluations. The scope of construction can divide the construction of smart cities. Individual key breakthroughs can also be carried out in an all-round manner. Within the scope of the ability of city construction, the two can also be considered at the same time. From the 


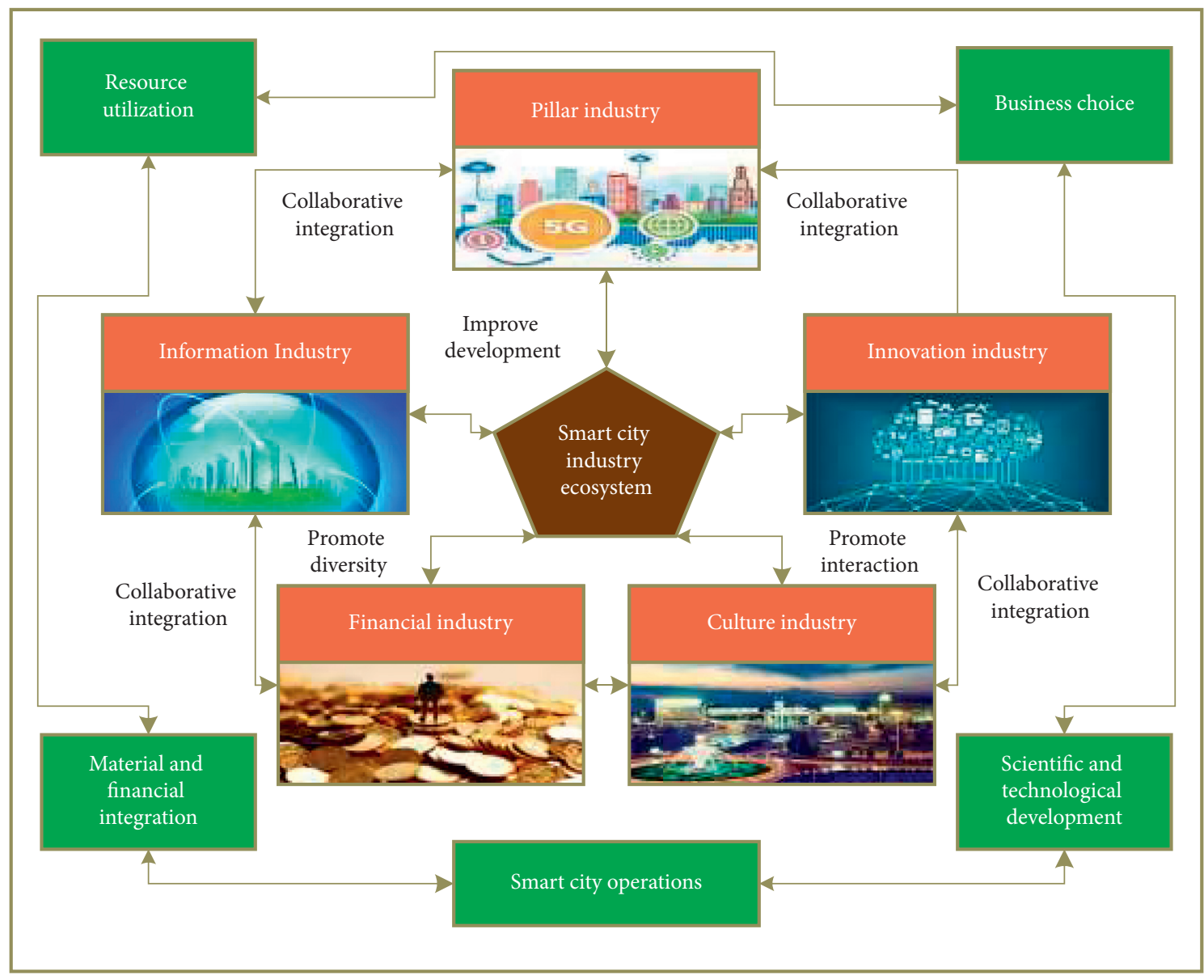

FIgURe 3: Smart city industrial ecosystem.

beginning of China's proposal for smart city construction to the present day, a total of three batches of smart city pilot lists have been released. Increased cities are taking smart cities as their construction goals, and the selected smart city themes are not the same. The first batch of cities participating in the construction, Shenzhen and Nanjing, were mainly led by innovation, and the pilot cities that participated in the construction afterwards mainly determined the development priorities according to the characteristics of the construction main body and future needs, so as to integrate the city's established development strategic goals and achieve smart cities. The construction of the building is organically combined. The sustainable development model of smart city can be divided into four categories:

(1) Innovative: at this stage, in the army of China's smart city construction, most cities regard innovation as an important driving force. Most of these cities already have a good development foundation and strong strength and regard the development of "smart" industries as a strategy to enhance cities, which are the key factors of status and competitive strength.

(2) The urban development of smart industries: in the process of urban development, such cities have gradually cultivated and formed characteristic industries with their own advantages and formed a complete upstream and downstream ecological environment in related fields. Therefore, these cities are more focused on maintaining and displaying their own advantages and intelligent industries. For the development of Kunshan, for example, the authors in [23] proposed focusing on accelerating the development of the Internet of Things, electronic technology, and other industries and promoting the construction of smart cities.

(3) Developing the wisdom and livelihood: such cities focus on the development of intelligent management and livelihood services to promote.

The wisdom of the city avoids the "big city disease" in small and medium-sized cities. The top priority of the development of smart cities is people-oriented, and its connotation is that all "people" of people's livelihood are the core, serving the "people" in the city as much as possible, so as to realize a green, safe, and efficient intelligent life.

(4) Development of information technology infrastructure: the construction of smart cities in this category focuses on information technology and information infrastructure. For example, with the help of advanced information technology, a modern and integrated administrative decision-making 
auxiliary system has been established. Operation in major enterprises and national administrative departments has proved that similar systems can effectively improve managers' work efficiency and decision-making ability.

The goal of constructing an evaluation index system for smart city sustainable development is to reflect the actual status of smart city sustainable development. When selecting indicators, pay attention to the representativeness and quantification of indicators, and build a comprehensive indicator system. Quantitative analysis of targets is done through quantifying indicators. The specific evaluation index system is shown in Table 1 .

\section{Results Analysis}

3.1. Model Analyses. The reliability test is to check the stability and consistency of the measurement results. This study uses SPSS software for internal reliability testing and reflects its reliability through Cronbach's $X$ coefficient. Assuming the reliability of the evaluation index system and each dimension as shown in Table 2, we considered the overall internal consistency of the evaluation index system. Cronbach's coefficient is 0.386 greater than 0.5 , and Cronbach's coefficients of the three common factors are all greater than 0.5 , so the index system meets certain reliability requirements. The specific indicators are shown in Table 2. Starting from the scoring coefficient matrix of exploratory factor analysis of the model, a comprehensive evaluation model is constructed with the variance contribution rate of each common factor as shown in Figure 4. The score coefficient matrix of each common factor and the variance contribution rate of each factor are shown in Figure 4,

According to the coupling and coordination model, systematically calculate the coupling and coordination between smart city construction, industrial development, and ecological protection, and finally determine the evaluation level. The results are shown in Figure 5. In terms of coupling degree, the 12 smart cities are in low-level coupling and high-level phases, respectively. In terms of coordination degree, except for Shenzhen, Beijing, and Shanghai, which have reached moderate coordination, the remaining cities are in low coordination. The overall development index of individual cities is low, and the evaluation index of the industrial development system is higher than that of the urban construction system, indicating that industrial development has failed to drive the development of infrastructure construction in smart cities. The proportion of the secondary industry in the industrial structure of some cities is still higher than that of the tertiary industry, which leads to a higher comprehensive evaluation index of the industrial development system than the urban construction system. This is because the proportion of emerging industries is very small and cannot become the pillars or leading enterprises of the cities. The endogenous power is insufficient, and the construction of smart cities fails to effectively promote the development of the industry.
3.2. Sustainability Analyses. The study used SPSS software for case clustering and cluster analysis of the comprehensive ranking of sustainable development of smart cities in provincial administrative regions. The results are shown in Figure 6. From the results of the above five-year factor equivalence and comprehensive evaluation score ranking, it can be intuitively found that the factor score and comprehensive rankings of category A-type cities are all in the top. It can be concluded that such areas are at the forefront of the country in the construction of smart cities, and a reference for the smart construction of other cities can be provided. Therefore, these areas are positioned as leading areas as the "leaders" for the sustainable development of smart city construction. The analysis of C-type cities shows that the development of cities is not stable enough, and there is no continuous growth. It is necessary to adjust their smart city construction models and other policies and find and deal with the problems in time. The economic level of such cities lags behind other provincial administrative regions. The construction of smart cities will inevitably be restricted and affected. However, such regions have a strong willingness to progress and develop. Development requires strong national support and the formulation of relevant policies. It can be seen that such provincial administrative regions should be positioned as catch-up areas, as a "catch-up army" for the sustainable development of smart city construction.

In the financial industry, funds and securities of capital suppliers are continuously transmitted in the process of financial operation through a series of investment and financing activities of financial entities. Various financial entities are formed according to the relationship between investment and financing. With the development of the economy, an intricate financial ecological network has been formed. The more the cooperation and the closer the cooperation in the financial industry, the higher the value of its products, the richer the variety, the more developed the market, and the stronger the financing ability. The more complex its industry is, the more stable it will be. The construction and development of smart cities should integrate "Internet + " into the financial industry, integrate and utilize the development resources of the Internet financial industry, truly realize the financial innovation driven by information technology, and use the Internet to reduce economic search costs and transaction costs macroscopically; focusing on externalities and the network effect makes use of the Internet to promote the positive development of management mechanisms, technological innovation, and corporate culture in the industry. Improve the financial entities required for each development link in the financial industry, so as to provide a stable chain of funds for urban development and industrial innovation in the process of complication, strengthen communication and cooperation among various financial entities, and realize the financial and information industry's complementary advantages and win-win cooperation. The city's intelligent construction also creates a good financial environment for industrial development. During the development of the industry, through the innovation of financial institutions, financial services, financial mechanisms, financial structures, and the expansion of financing channels, optimize the industrial 
TABLE 1: Evaluation index system.

\begin{tabular}{|c|c|c|c|}
\hline Smart city construction & Urbanization & $\begin{array}{l}\text { A1: investment in fixed assets of the whole society } \\
\text { A2: urban road area } \\
\text { A3: drainage pipe length } \\
\text { A4: passenger traffic of the whole society } \\
\text { A5: total volume of post and telecommunications services } \\
\text { A6: urbanization rate } \\
\text { A7: urban population density } \\
\text { A8: per capita disposable income of urban residents }\end{array}$ & $\begin{array}{l}\text { Million dollars } \\
\text { Square kilometers } \\
\text { Kilometers } \\
\text { Ten thousands } \\
\text { Million dollars } \\
\% \\
\% \\
\text { Yuan }\end{array}$ \\
\hline $\begin{array}{l}\text { Composite index } \\
\text { industrial development }\end{array}$ & $\begin{array}{l}\text { Industrial structure } \\
\begin{array}{c}\text { Technology support } \\
\text { capability }\end{array}\end{array}$ & $\begin{array}{l}\text { B1: the amount of investment in fixed assets of information } \\
\text { technology and Internet companies } \\
\text { B2: number of information technology and software companies } \\
\text { B3: information technology, software practitioners } \\
\text { B4: tertiary industry output value as a percentage of GDP } \\
\text { B5: the proportion of output value of secondary industry to GDP } \\
\text { B6: patent authorization } \\
\text { B7: number of national key laboratories } \\
\text { B8: R\&D internal expenditure } \\
\text { B9: number of R\&D researchers }\end{array}$ & $\begin{array}{l}\text { Million dollars } \\
\text { Pc } \\
\text { People } \\
\% \\
\text { Item } \\
\text { Pc } \\
\text { Million dollars } \\
\text { People } \\
\%\end{array}$ \\
\hline $\begin{array}{l}\text { Composite index ecological } \\
\text { protection } \\
\text { comprehensive index }\end{array}$ & $\begin{array}{l}\text { Environmental } \\
\text { protection }\end{array}$ & $\begin{array}{l}\text { C1: green coverage rate in built-up area } \\
\text { C2: park green area per capita } \\
\text { C3: industrial solid waste generation } \\
\text { C4: comprehensive utilization of industrial solid waste }\end{array}$ & $\begin{array}{l}\text { Square meter } \\
\text { Ten thousand } \\
\text { tons } \\
\text { Ten thousand } \\
\text { tons } \\
\text { Million dollars }\end{array}$ \\
\hline
\end{tabular}

TABle 2: Consistent reliability test index.

\begin{tabular}{lcccc}
\hline Types & Factor 1 & Factor 2 & Factor 3 & Overall \\
\hline Cronbach's $\alpha$ coefficient & 0.894 & 0.843 & 0.867 & 0.886 \\
\hline
\end{tabular}

upgrading model, improve the services of urban financial organizations, and form a financial center with a reasonable layout-industry as a financial entity. The characteristics and capital advantages of Internet companies have technological and innovation advantages. As a huge platform for the development of the financial industry, cities have pipeline advantages and many mobile terminals and ultimately achieve the integration of industry and city. Financial IT cost analysis is shown in Figure 7.

3.3. Empirical Analyses. The financial cloud has the characteristics of huge investment in the early stage of business development, and the short-term and short-term income may not be fully guaranteed. Many companies rely on venture capital funds or through the stock market to obtain funds to ensure the company's sustainable development. Figure 8 is the net profit compiled according to the smart city's financial reports in the past years. We have seen a negative net profit since 2011. Now with the support of financial cloud technology, you do not have to worry about changes in business cycles or customer groups that cause problems with working capital. You can calmly face changes in various market environments.

To evaluate an object, a certain decision-making unit needs to be selected, and certain criteria need to be adopted in this selection. The specific selection principle should ensure that the selected decision-making unit can achieve the same when it is in the same external environment. Tasks achieve the same input and output. There are three ways to select DMU in the evaluation process of smart cities, namely, vertical and horizontal comparison and vertical and horizontal comprehensive comparison. This article uses a longitudinal comparison to select the DMU. Based on the obtained data, this paper selects the comprehensive evaluation of the urban construction in the past three years and analyzes the results of the smart city construction in Shanghai in the past three years based on scientific results. Based on the above analysis, it can be found that the smart city construction has achieved certain results through input and output. Pay attention to the human cost, infrastructure, and capital input, and the corresponding output of smart government, smart economy, smart life, and smart human literacy is efficient. With continuous investment in major factors, the effectiveness of the government's DMU fluctuates around 1, which also proves that the principle of effectiveness can be met in the selection of input and output indicators. In further analysis of factor productivity, we can see that all major factors are effective, and the application of new technologies and innovations in production and management has achieved good results. This is also further showing that if the government, major financial institutions, and other stakeholders attach importance to the investment in various elements, they can achieve good results to a large extent. The regression test results are shown in Figure 9. 


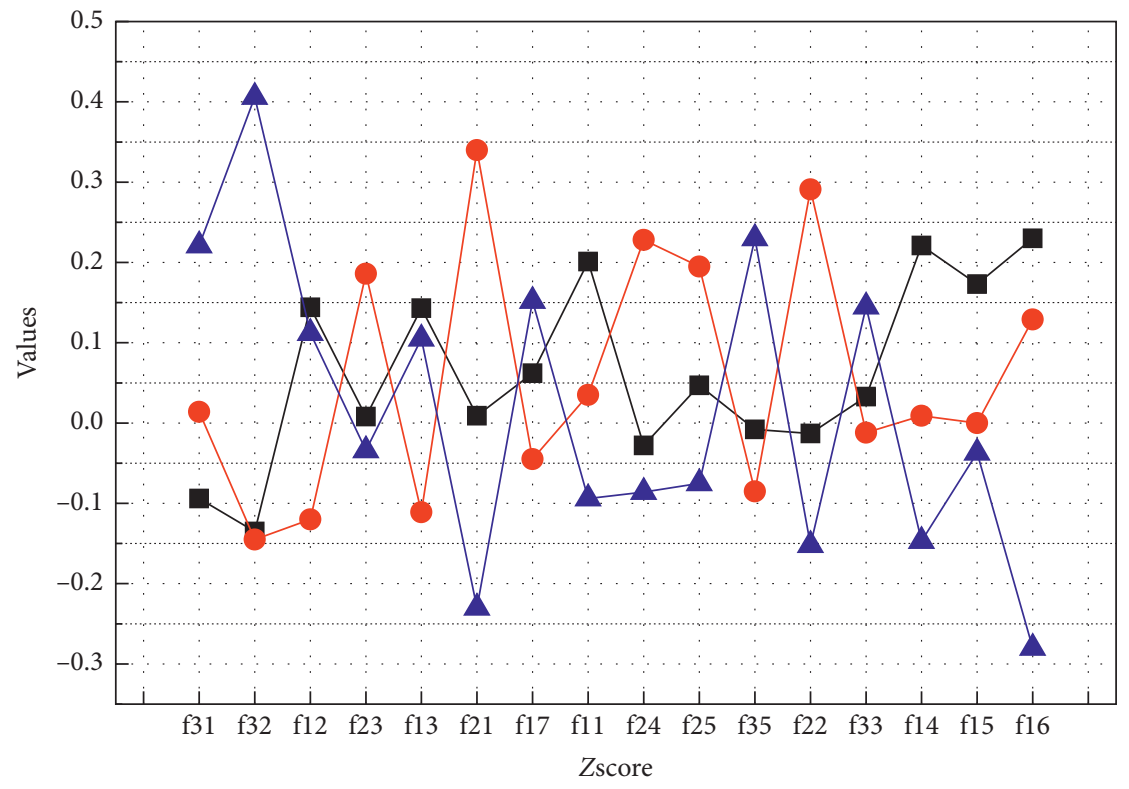

$-\mathrm{fl}$

- $\mathrm{f} 2$

$-\mathrm{f} 3$

FIGURE 4: Score coefficient and variance contribution rate.

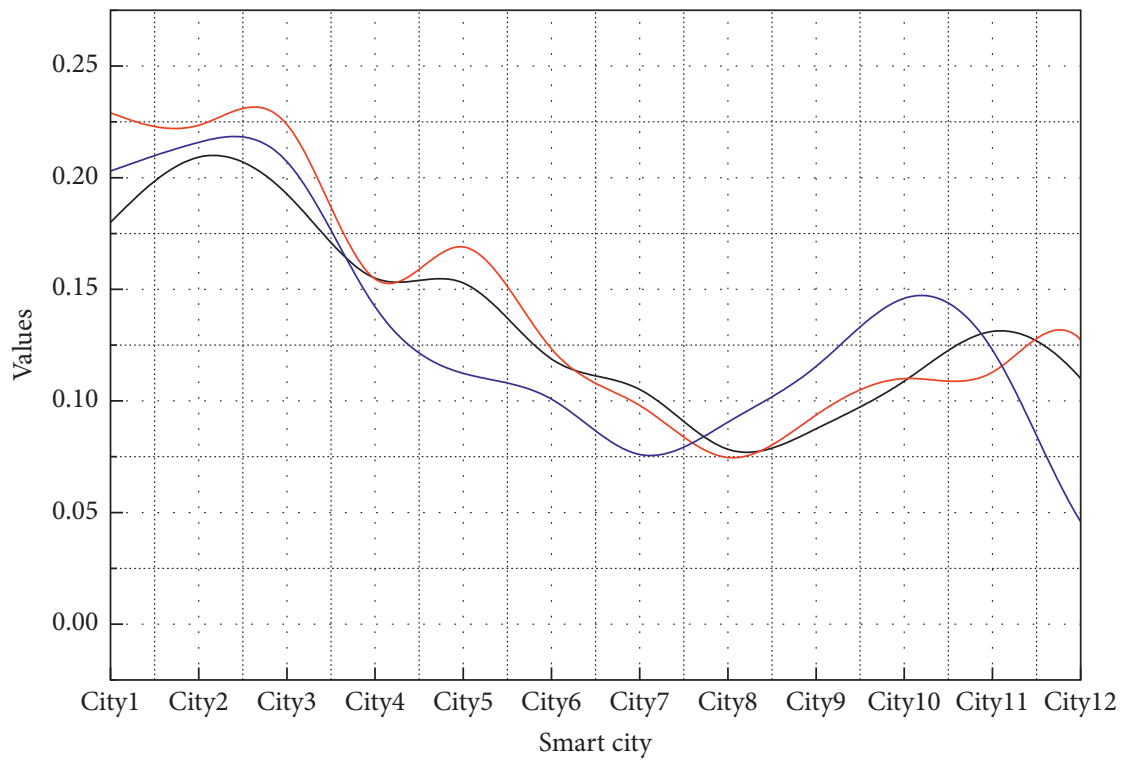

- Comprehensive development index $T$

- Coupling degree $C$

- Coordination $D$

FIgURE 5: Smart city industry-city integration and evaluation level. 


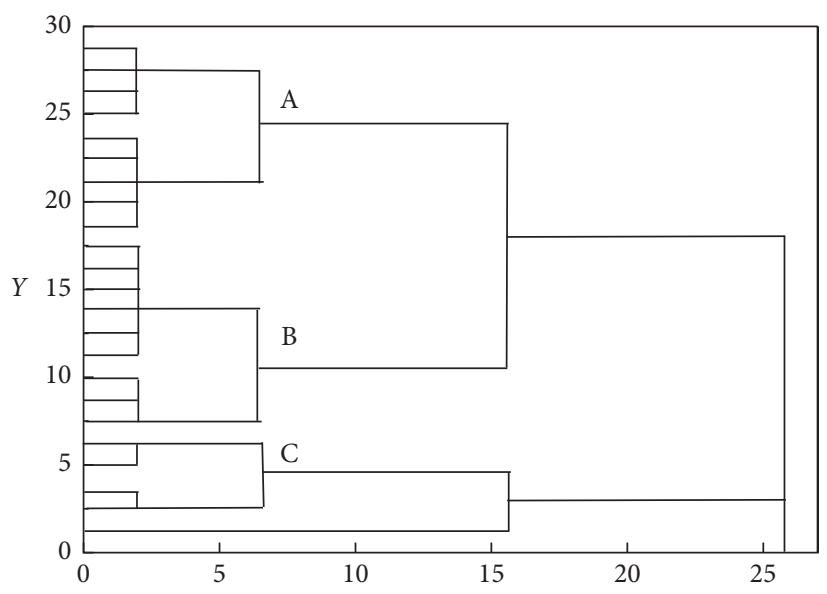

Figure 6: Horizontal clustering tree diagram.
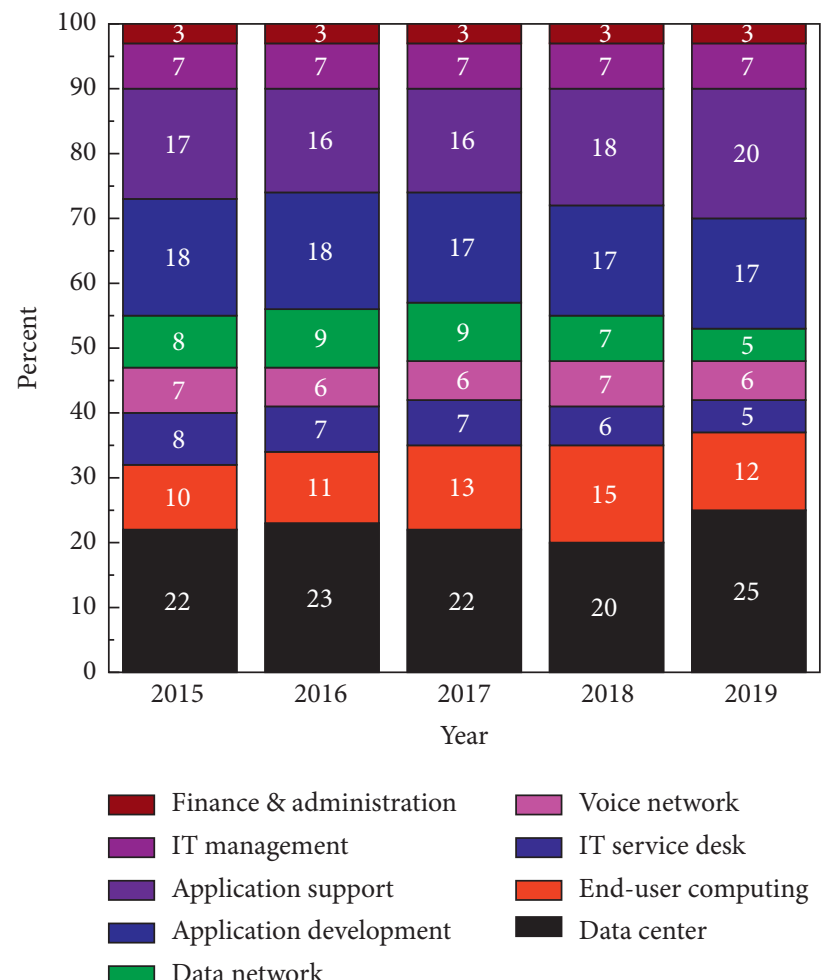

network

FIGURE 7: Distribution of IT costs.

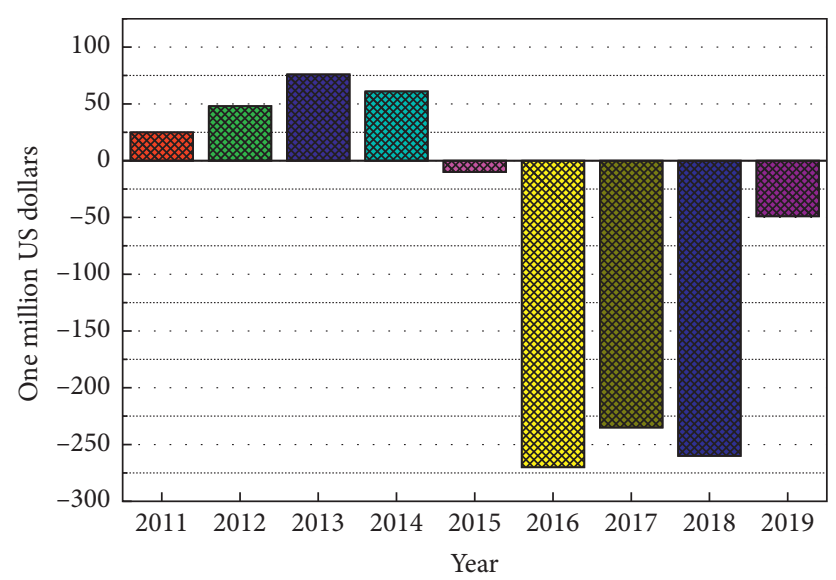

Figure 8: City net profit over the years. 


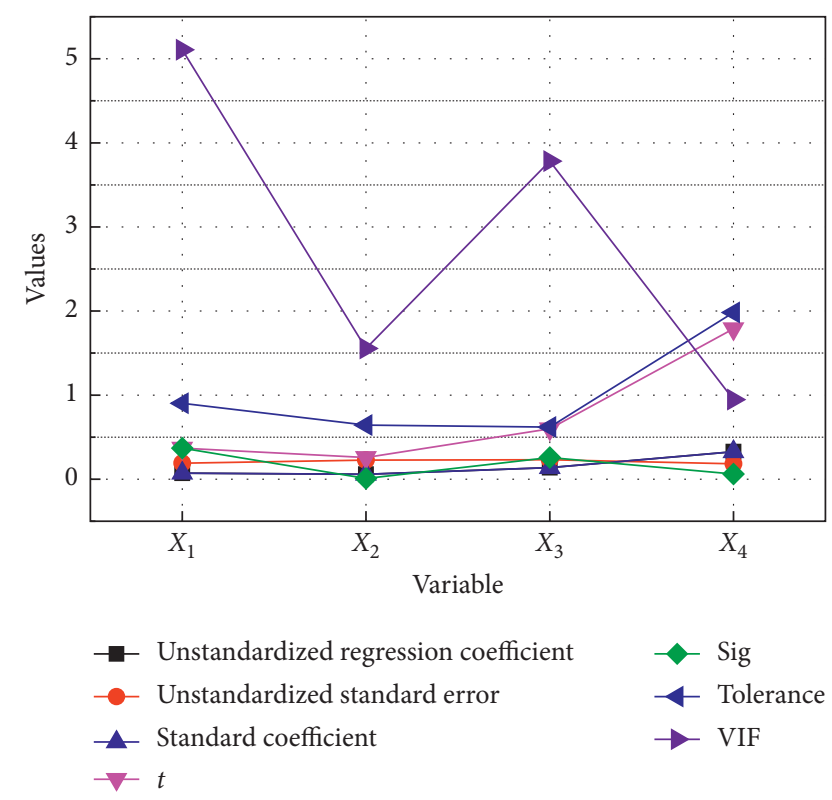

Figure 9: Regression coefficient test and significance level.

\section{Conclusion}

This article first discusses the relationship between smart cities and finance and existing models based on existing relevant theories and literature. By comparing and analyzing the status of smart cities and financial clouds at home and abroad, this paper applies financial cloud intelligence to build smart cities. It has laid the foundation for empirical analysis and model innovation. Theoretical research of financial technology and smart city is integrated with each other to study and analyze the health and perfect sustainable road of smart city. The problems in the sustainable development of smart cities should be solved from the aspects of economy, human problems, environmental science, urban infrastructure, and ecological environment. Explore the innovation of the smart city model based on the "financial cloud" perspective. In order to achieve the sustainable development goals of smart cities, explore the dynamic mechanism of sustainable development of smart cities, through the analysis of the structure and elements of smart cities, and improve the construction of financial ecological chain in order to achieve the goal of model innovation. Finally, this paper proposes a way to realize the integration of smart city and financial cloud, which has certain guiding significance for the sustainable development of the smart city.

\section{Data Availability}

The data used to support the findings of this study are available from the corresponding author upon request.

\section{Conflicts of Interest}

The authors declare that they have no conflicts of interest regarding the publication of this paper.

\section{Acknowledgments}

This work was supported by the General Project of the National Natural Science Foundation of China (Nos. 71874037 and 71673062) and Natural Science Foundation of Guangdong Province (No. 2018A030313397).

\section{References}

[1] C. Kakderi, N. Komninos, and P. Tsarchopoulos, "Smart cities and cloud computing: lessons from the STORM CLOUDS experiment," Journal of Smart Cities, vol. 1, no. 2, pp. 4-13, 2019.

[2] P. Tsarchopoulos, N. Komninos, and C. Kakderi, "Accelerating the uptake of smart city applications through cloud computing. World Academy of Science, Engineering and Technology," International Journal of Social, Behavioral, Educational, Economic, Business and Industrial Engineering, vol. 11, no. 1, pp. 129-138, 2017.

[3] N. Komninos, C. Kakderi, A. Panori, and P. Tsarchopoulos, "Smart city planning from an evolutionary perspective," Journal of Urban Technology, vol. 26, no. 2, pp. 3-20, 2019.

[4] N. P. Rana, S. Luthra, S. K. Mangla, R. Islam, S. Roderick, and Y. K. Dwivedi, "Barriers to the development of smart cities in Indian context," Information Systems Frontiers, vol. 21, no. 3, pp. 503-525, 2019.

[5] G. Trencher and A. Karvonen, "Stretching "smart": advancing health and well-being through the smart city agenda," Local Environment, vol. 24, no. 7, pp. 610-627, 2019.

[6] S. P. Mohanty, U. Choppali, and E. Kougianos, "Everything you wanted to know about smart cities: the internet of things is the backbone," IEEE Consumer Electronics Magazine, vol. 5, no. 3, pp. 60-70, 2016.

[7] Y. Mehmood, F. Ahmad, I. Yaqoob, A. Adnane, M. Imran, and S. Guizani, "Internet-of-things-based smart cities: recent advances and challenges," IEEE Communications Magazine, vol. 55, no. 9, pp. 16-24, 2017.

[8] M. Angelidou, "The role of smart city characteristics in the plans of fifteen cities," Journal of Urban Technology, vol. 24, no. 4, pp. 3-28, 2017.

[9] M. Sookhak, H. Tang, Y. He et al., "Security and privacy of smart cities: a survey, research issues and challenges," IEEE Communications Surveys \& Tutorials, vol. 21, no. 2, pp. 1718-1743, 2018.

[10] S. Berke, "The sustainable development of data-driven smart cities: citizen-centered urban governance and networked digital technologies," Geopolitics, History, and International Relations, vol. 11, no. 2, pp. 122-127, 2019.

[11] M. Masera, E. F. Bompard, F. Profumo, and N. Hadjsaid, "Smart (electricity) grids for smart cities: assessing roles and societal impacts," Proceedings of the IEEE, vol. 106, no. 4, pp. 613-625, 2018.

[12] A. Panori, A. González-Quel, M. Tavares et al., "Migration of applications to the Cloud: a user-driven approach," Journal of Smart Cities, vol. 2, no. 1, pp. 16-27, 2019.

[13] J. Xie, H. Tang, T. Huang et al., "A survey of blockchain technology applied to smart cities: research issues and challenges," IEEE Communications Surveys \& Tutorials, vol. 21, no. 3, pp. 2794-2830, 2019.

[14] E. F. Z. Santana, A. P. Chaves, M. A. Gerosa et al., "Software platforms for smart cities: concepts, requirements, challenges, and a unified reference architecture," ACM Computing Surveys, vol. 50, no. 6, pp. 1-37, 2017. 
[15] X. Kong, X. Liu, B. Jedari, M. Li, L. Wan, and F. Xia, "Mobile crowdsourcing in smart cities: technologies, applications, and future challenges," IEEE Internet of Things Journal, vol. 6, no. 5, pp. 8095-8113, 2019.

[16] D. Eckhoff and I. Wagner, "Privacy in the smart cit$\mathrm{y}$-applications, technologies, challenges, and solutions," IEEE Communications Surveys \& Tutorials, vol. 20, no. 1, pp. 489-516, 2017.

[17] A.-M. Valdez, M. Cook, P.-A. Langendahl, H. Roby, and S. Potter, "Prototyping sustainable mobility practices: usergenerated data in the smart city," Technology Analysis \& Strategic Management, vol. 30, no. 2, pp. 144-157, 2018.

[18] H. Xu and X. Geng, "People-centric service intelligence for smart cities," Smart Cities, vol. 2, no. 2, pp. 135-152, 2019.

[19] J. Arthi, "Bottom billion strategy-smart Villages," Asian Journal of Multidimensional Research (AJMR), vol. 7, no. 1, pp. 63-66, 2018.

[20] A. Gharaibeh, M. A. Salahuddin, S. J. Hussini et al., "Smart cities: a survey on data management, security, and enabling technologies," IEEE Communications Surveys \& Tutorials, vol. 19, no. 4, pp. 2456-2501, 2017.

[21] N. F. Alwan and M. K. AL-Nuaimi, "The role and important of internet of things in building sustainable city," Engineering and Technology Journal, vol. 36, no. 1, pp. 22-29, 2018.

[22] M. Aamir, S. Masroor, Z. A. Ali, and B. T. Ting, "Sustainable framework for smart transportation system: a case study of karachi," Wireless Personal Communications, vol. 106, no. 1, pp. 27-40, 2019.

[23] S. P. Caird and S. H. Hallett, "Towards evaluation design for smart city development," Journal of Urban Design, vol. 24, no. 2, pp. 188-209, 2019. 